\title{
A Study of Start-Up Characteristics of a Potassium Heat Pipe from the Frozen State
}

Jong Hoon Jang

Sverdrup Technology, Inc.

Lewis Research Center Group

Brook Park, Ohio

April 1992

Prepared for

Lewis Research Center

Under Contract NAS3-25266
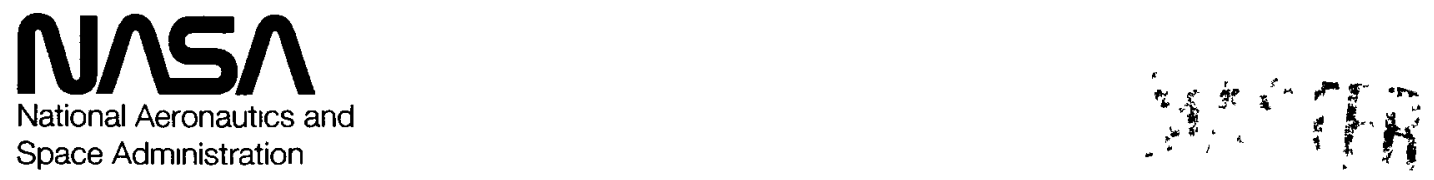

Space Admınistration 


\section{DISCLAIMER}

This report was prepared as an account of work sponsored by an agency of the United States Government. Neither the United States Government nor any agency Thereof, nor any of their employees, makes any warranty, express or implied, or assumes any legal liability or responsibility for the accuracy, completeness, or usefulness of any information, apparatus, product, or process disclosed, or represents that its use would not infringe privately owned rights. Reference herein to any specific commercial product, process, or service by trade name, trademark, manufacturer, or otherwise does not necessarily constitute or imply its endorsement, recommendation, or favoring by the United States Government or any agency thereof. The views and opinions of authors expressed herein do not necessarily state or reflect those of the United States Government or any agency thereof. 


\section{DISCLAIMER}

Portions of this document may be illegible in electronic image products. Images are produced from the best available original document. 


\title{
A STUDY OF START-UP CHARACTERISTICS OF A POTASSIUM HEAT PIPE FROM THE FROZEN STATE
}

\author{
Jong Hoon Jang \\ Sverdrup Technology, Inc. \\ Lewis Research Center Group \\ Brook Park, Ohio 44142
}

\section{ABSTRACT}

The start-up characteristics of a potassium heat pipe were studied both analytically and experimentally. Using the radiation heat transfer mode the heat pipe was tested in a vacuum chamber. The transition temperature calculated for potassium was then compared with the experimental results of the heat pipe with various heat inputs. These results show that the heat pipe was inactive until it reached the transition temperature. In addition, during the start-up period, the evaporator experienced dry-out with a heat input smaller than the capillary limit calculated at the steady state. However, when the working fluid at the condenser was completely melted, the evaporator was rewetted without external aid. The start-up period was significantly reduced with a large heat input.

\section{NOMENCLATURE}

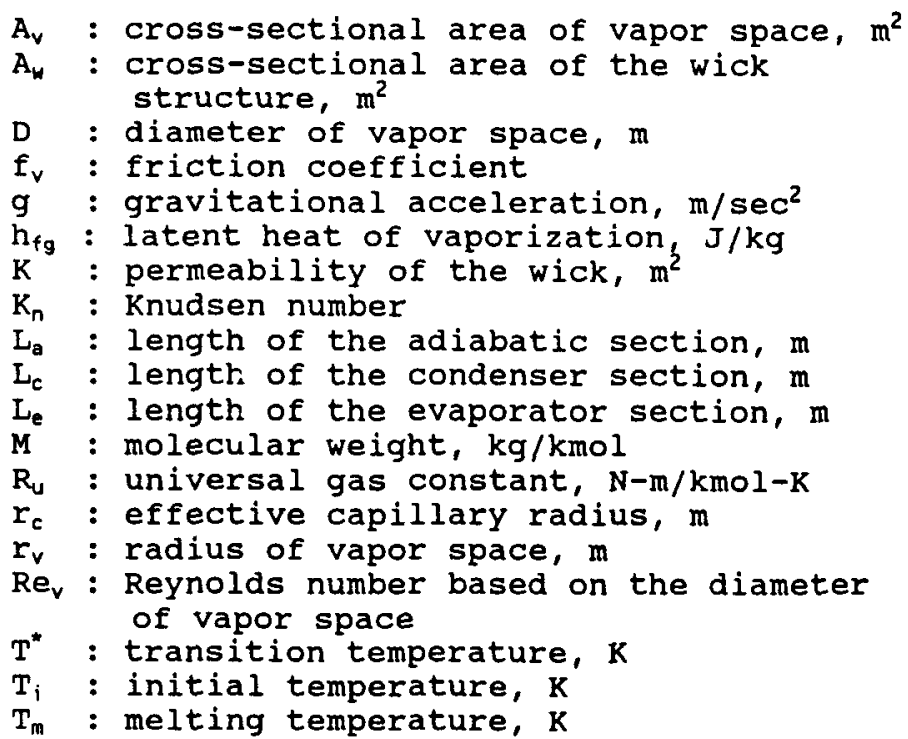

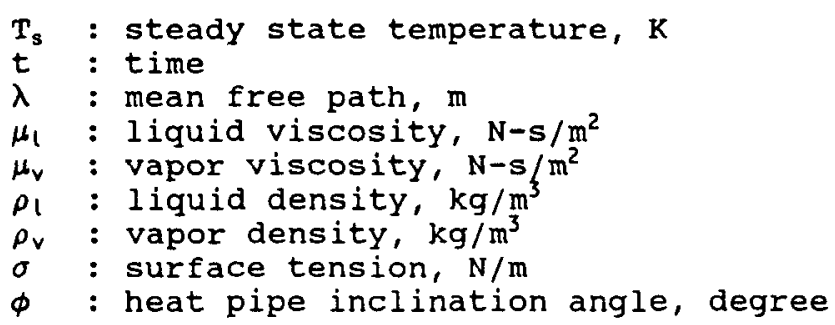

\section{INTRODUCTION}

Because heat pipes are effective devices for transporting large amounts of heat with small temperature gradients, they have been considered as elements of heat rejection systems for space power systems (Juhasz, 1991) and as heat receivers for solar dynamic space power systems (Baker et al., 1990; Fujiwara et al., 1990). For high temperature applications, the working fluids in most liquid metal heat pipes are entirely in the solid state at ambient temperature while pressure in the vapor space is extremely low so that free molecular flow conditions prevail. Unlike for low temperature heat pipes, these conditions may cause the heat pipe to fail to operate; they also complicate mathematical models of liquid metal heat pipes during the start-up period.

The start-up process for potassium and sodium heat pipes from the frozen state has been experimentally investigated by Deverall et al. (1970), Tolubinsky et al. (1982), and Ivanovskii et al. (1982). Vapor temperatures measured by Ivanovskii et al. (1982) and Faghri et al. (1991) indicated that different flow regimes existed in the vapor space. Based on those experimental results, mathematical models have been devised by Jang (1988) and Jang et al. (1990) to describe the start-up behavior. The start-up process is rather complicated due to the many phase changes of the working substance, for instance from the 
solid to vapor state, and different flow regimes in the vapor space, for instance from the free molecular to the continuum regime as shown in Figure 1. The mathematical model presented by Jang et al. (1990) exemplifies the complexity of the governing equations and boundary conditions for each start-up period. Thus, simplification of the mathematical model is needed to obtain solutions within reasonable computer time.

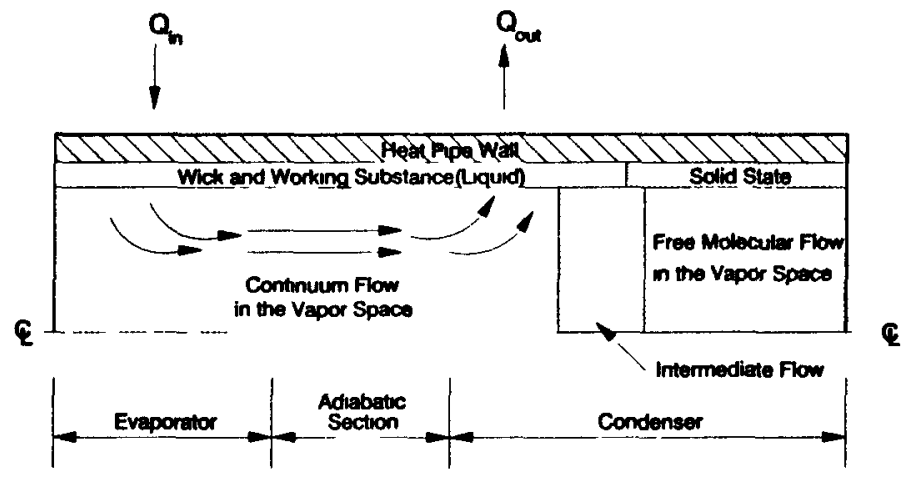

Fig. 1 Description of the frozen start-up of liquid metal heat pipes.

To simplify the mathematical model during the frozen start-up, Jang (1988) and Jang et al. (1990) suggested that the adiabatic boundary condition could be applied at the interface between the wick structure and the vapor space when free molecular flow prevails in the vapor space. An equation was derived to calculate the transition temperature using kinetic theory. However, a comparison between the calculated transition temperature and any experimental result was not made. Also, the behavior of heat pipes at the transition temperature range was not investigated.

During the start-up period, a part of the working fluid is still in the solid state and the heat pipes are partially operational. Also, the vapor flowing to the condenser section may freeze again at the interface of the adjacent condenser section. Thus, dry-out at the wick structure could occur with much less heat input than at steady state operation; it takes considerable time for heat pipes to become fully operational. However, no analytical or numerical model in the archival literature predicts dry-out during the startup period. Thus, qualitative information on the difference between the capillary limits during the start-up period and at the steady state is needed to specify the proper heat input during the start-up period. This heat input could minimize the start-up period without dry-out at the wick structure.

The objective of this paper is to present analytical and experimental results of the operation of a potassium heat pipe during the start-up period which could be used to simplify the mathematical model and to achieve the successful start-up of liquid metal heat pipes. First, the transition temperatures from free molecular flow to continuum flow for potassium and sodium were calculated with various vapor space diameters. Then the transition temperature for the potassium working fluid was compared with the experimental results. Finally, the capillary limits calculated for various operating temperatures were compared to the capillary limit obtained during the start-up test.

\section{ANALYSIS}

\section{Transition Temperature}

Since heat transfer is negligible within the free molecular flow regime, a simplification of the mathematical model could be achieved by neglecting the free molecular flow in the vapor space. For this purpose, some criterion is needed to define the region where free molecular flow prevails. The ratio of the mean free path to a characteristic length is the parameter used to define the flow regime. This parameter is called the knudsen number (Eckert and Drake, 1972), and is defined by

$$
K_{\mathrm{n}}=\frac{\lambda}{D}
$$

where the diameter of the vapor space, $D$, is used as a characteristic length and $\lambda$ is the mean free path. When the mean free path is very small in comparison with a characteristic length of the vapor space, i.e., $K_{n} \leq 0.01$, it is assumed that continuum flow is established.

For $k_{n}=0.01$, the transition temperature, $T^{*}$, from free molecular flow to continuum flow corresponding to a given characteristic length for the vapor space is derived using the kinetic theory of gases as follows (Jang, 1988):

$$
T^{*}=\frac{\pi}{2 \times 10^{-4}} \frac{M}{R_{u}}\left(\frac{\mu_{v}}{\rho_{v} D}\right)^{2}
$$

where $M$ is the molecular weight of the working fluid, $R_{u}$ is the universal gas constant, $\mu_{v}$ is the vapor viscosity, and $\rho_{v}$ is the vapor density. To obtain $T^{*}$ numerous iterations are required because the physical properties are temperature-dependent. The continuum flow regime is assumed to be prevalent when the vapor temperature is greater than the transition temperature. The transition temperatures for potassium and sodium were calculated using Equation (2). The transition temperature derreases with increasing vapor space diameter as shown in Figure 2. In addition, the transition temperature of sodium is greater than that of potassium by about $100 \mathrm{~K}$.

Maximum Capillary Limits

The vapor flow was assumed to be laminar and incompressible since the Reynolds number for the maximum heat transfer of 1250 watts used for the experiment was less than 2300 . Uniform heat flux distributions along the 


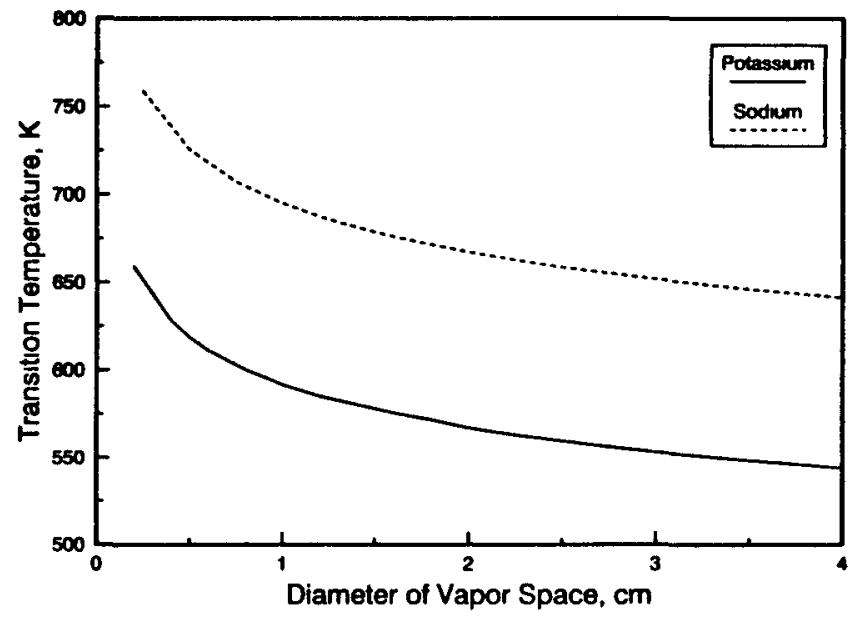

Fig. 2 Transition temperatures with various vapor space diameters for potassium and sodium.

evaporator and condenser sections were assumed. Since the actual radii of curvature of the meniscus at the liquid-vapor interface are unknown, the maximum possible capillary limits were calculated for a given geometry of the wick structure at the steady state conditions. The capillary limitation was determined using the following expressions (Chi, 1976):

$$
\begin{aligned}
& Q_{c, \max }=\frac{(Q L)_{c, \max }}{0.5 L_{a}+L_{a}+0.5 L_{c}} \\
& (Q L)_{c, \max }=\frac{\frac{2 \sigma}{r_{c}}-\rho_{1} g d_{v} \cos \phi}{F_{1}+F_{v}}
\end{aligned}
$$

where the frictional coefficients for the liquid and vapor flows are defined as follows:

$$
\begin{gathered}
F_{1}=\frac{\mu_{1}}{K A_{w} \rho_{1} h_{f g}} \\
F_{v}=\frac{\left(f_{v} R e_{v}\right) \mu_{v}}{2 I_{v}{ }^{2} A_{v} \rho_{v} h_{f g}}
\end{gathered}
$$

\section{EXPERIMENTAL SETUP}

A potassium heat pipe with a screen wick structure was used to conduct the experimental studies in a vacuum chamber. The total length of the heat pipe was $45.72 \mathrm{~cm}$ and the outer diameter of the heat pipe was $2.54 \mathrm{~cm}$. The heat pipe wall and wick structure were made of stainless steel. Table 1 shows dimensions and materials of the potassium heat pipe.

To measure the surface temperature of the heat pipe, a total of nine chromel-alumel thermocouples (Type $K$ ) were installed on the surface of the heat pipe wall; each thermocouple was alternately placed 180 degrees apart along the circumference as shown in Figure 3 . In addition, two thermocouples were placed at

Table 1. Physical Dimensions of the Potassium Heat Pipe.

Pipe wall material

Pipe O.D.

Pipe I.D.

Pipe length

Wick material

Screen Mesh number

Wick thickness

wick wire diameter

Porosity of wick

Vapor space diameter

Working fluid

Fluid charge

Evaporator length

Condenser length

Cooling Shroud

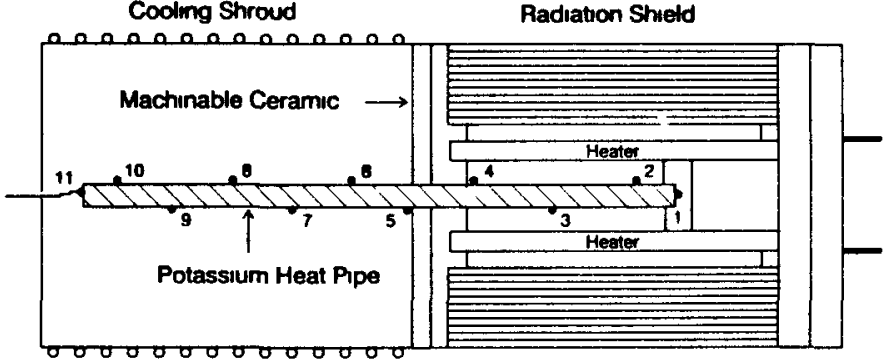

- Type K Thermocouplo (Caromer Aumen)

Location of thermocouples from end cap of the evaporator
$\begin{array}{llll}\text { TC \# } & \text { Location, cm } & \text { TC \# } & \text { Location, cm } \\ 1 & 00 & 7 & 2794 \\ 2 & 254 & 8 & 3302 \\ 3 & 762 & 9 & 381 \\ 4 & 127 & 10 & 4318 \\ 5 & 1778 & 11 & 4572 \\ 6 & 2286 & & \end{array}$

Fig. 3 Configuration of heater, cooling shroud, and radiation shields and thermocouple locations.

the end caps of the evaporator and condenser sections. All thermocouples were connected to a data logger (Fluke 2880A) and the data was stored on a personal computer using communication software. Temperatures were measured every 30 seconds, with the temperature measurement accuracy of $\pm 0.6 \mathrm{~K}$.

A silicon carbide heater applied heat by radiative heat transfer. The length of heating element was $20.32 \mathrm{~cm}$ with an outer diameter of $5.4 \mathrm{~cm}$. The electric resistance of the heater was 1.56 ohms at ambient temperature. Figure 3 illustrates the configuration of the heater and heat pipe setup. Machinable ceramic parts were used to maintain the gap between the heater and the heat pipe. A digital multimeter (Fluke $8520 \mathrm{~A}$ ) and ammeter were installed to measure electrical power to the heater. Heat 
input measurement accuracy is \pm 2.5 of heat input. The heater was insulated by a radiation shield.

A copper cooling shroud extracted heat energy from the condenser section as shown in Figure 3. The length of the shroud was 35.56 $\mathrm{cm}$ with a diameter of $10.16 \mathrm{~cm}$. Also, a 0.635 $\mathrm{cm}$ diameter copper tube was wrapped at about $2.54 \mathrm{~cm}$ intervals to circulate coolant. A mixture of 50 volume percent ethylene glycol in water was used for coolant. The inside surface was painted with black paint. one thermocouple was installed at the center of the shroud to measure the shroud temperature. The inlet and outlet coolant temperatures and flow rate were measured to determine total heat transport. A variable area flow meter measured the flow rate with an uncertainty of $\pm 1 \mathrm{ml} / \mathrm{sec}$. A chiller supplied coolant at a constant inlet temperature. The temperature stability of this unit is $\pm 0.1 \mathrm{~K}$.

To simulate space environments, where radiation is the major heat transfer mode, the entire experimental setup was placed in the vacuum chamber, as shown in Figure 4. The vacuum chamber provided a physical barrier in case there was leaking of the working fluid. Prior to testing the heat pipe, the chamber was pumped down to a pressure of $3.5 \times 10^{-4} \mathrm{~mm}$ Hg (Torr), which was the minimum pressure achieved. During the tests of the heat pipe, this pressure was maintained in the chamber.

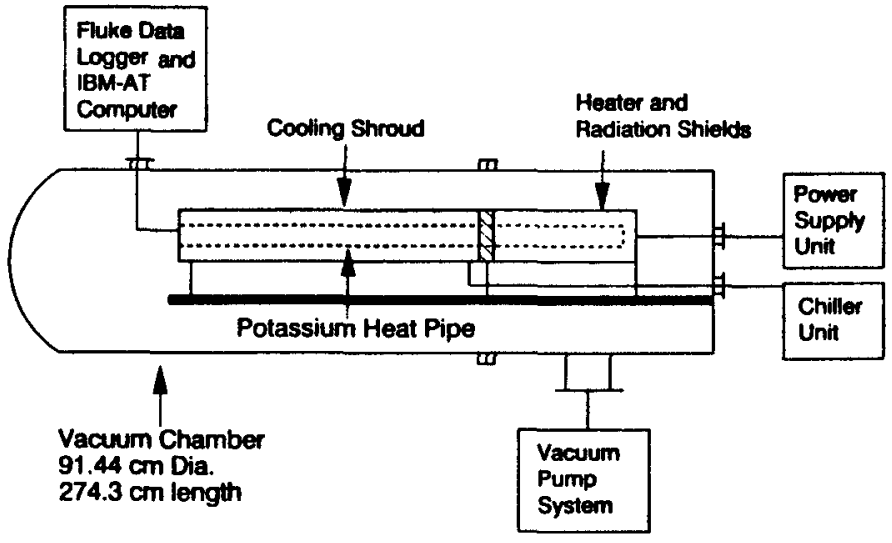

Fig. 4 Schematic diagram of experimental setup for a potassium heat pipe.

\section{RADIATION SHIELD AND HEAT LOSS}

A seventeen-layer radiation shield reduced heat losses from the silicon carbide heater. Each layer was made of $0.0127 \mathrm{~cm}$ thick stainless steel sheet and separated by an eight mesh screen made of $0.0432 \mathrm{~cm}$ diameter wires to keep a uniform gap. For convenience of fabrication, a single layer of stainless steel together with a single layer of screen was spirally rolled to form the seventeen layers. The ends of the sheet were then welded. To measure temperature drops across the seventeen-layer radiation shield, six chromelalumel thermocouples were installed at the first and last layers.
Even though the radiation shield was installed to minimize the heat losses from the heater in the radial direction, the heat losses at the ends of the heater in the axial direction still occurred through the ceramic disks which are located between the cooling shroud and the heater, as shown in Figure 3 . The axial heat losses from the heater end to the adjacent cooling shroud increased the coolant outlet temperature. Thus, the total heat transport to the cooling shroud consisted of the heat transfer from both the heat pipe and the heater end. Heat transport from the heater end to the cooling shroud was estimated.

For this purpose, the heat pipe was replaced by a hollow pipe which had the same size and same stainless steel material. Then the experimental setup was installed in the same vacuum chamber and maintained in the same environmental condition. All tests were conducted using various heat inputs in the vacuum environment. Also, coolant was circulated at a constant flow rate of $27 \mathrm{ml} / \mathrm{sec}$ through the cooling shroud. At the steady state, the heat transport from the heater to the cooling shroud was estimated using the temperature difference between the inlet and outlet temperatures of the coolant and the coolant flow rate for various test cases. Then the heat transport to the coolant verse temperatures measured at the inner layer of the radiation shields was plotted as shown in Figure 5 .

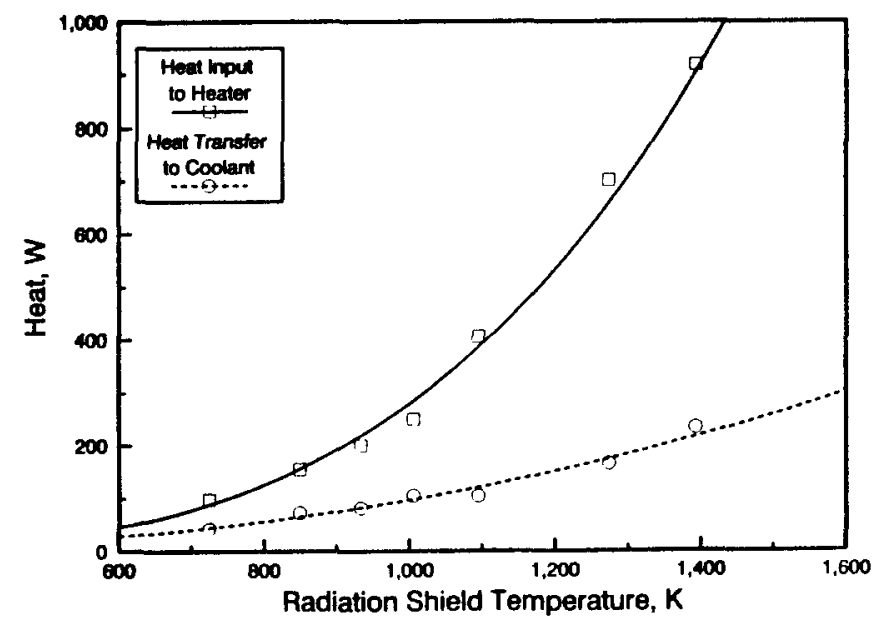

Fig. 5 Test results of the experimental setup without the heat pipe.

During the actual heat pipe tests, the net heat transport through the heat pipe was calculated. Total heat transport was estimated using the temperature difference between the inlet and outlet temperatures of the coolant and the coolant flow rate. Also, the heat transport from the heater end to the cooling shroud was estimated using Figure 5 ; this value was then subtracted from the total heat transport to obtain the net heat transport through the heat pipe. Energy balances made using this method showed that heat losses from the experimental setup were about 26.5 to 42.8 percent of the heat input, depending on the operating temperature. These heat losses are 
relatively larger than those in low temperature heat pipe tests.

\section{RESULTS AND DISCUSSION}

To investigate the start-up behavior, the potassium heat pipe was tested using a constant heat input of 500 watts in a vacuum environment. The surface temperature distributions during this test and the transition temperature of $567 \mathrm{~K}$ calculated using Equation (2) for the vapor space diameter of the potassium heat pipe are shown in Figures $6 \mathrm{a}$ and $6 \mathrm{~b}$. Also, the melting temperature $(337 \mathrm{~K})$ of the potassium working fluid is illustrated. Since the surface temperatures at the evaporator are greater than the vapor temperature, an exact comparison cannot be achieved without measuring the vapor temperature directly. However,

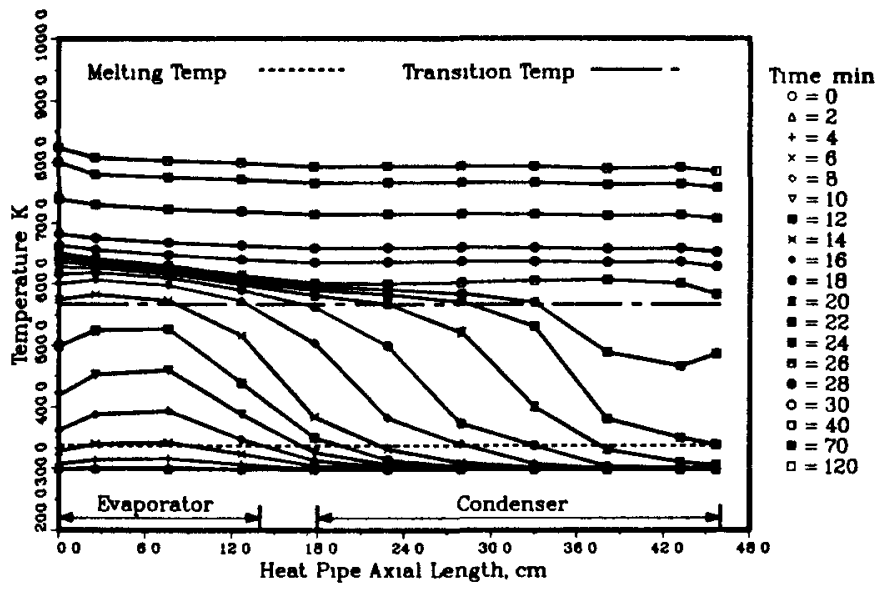

(a)

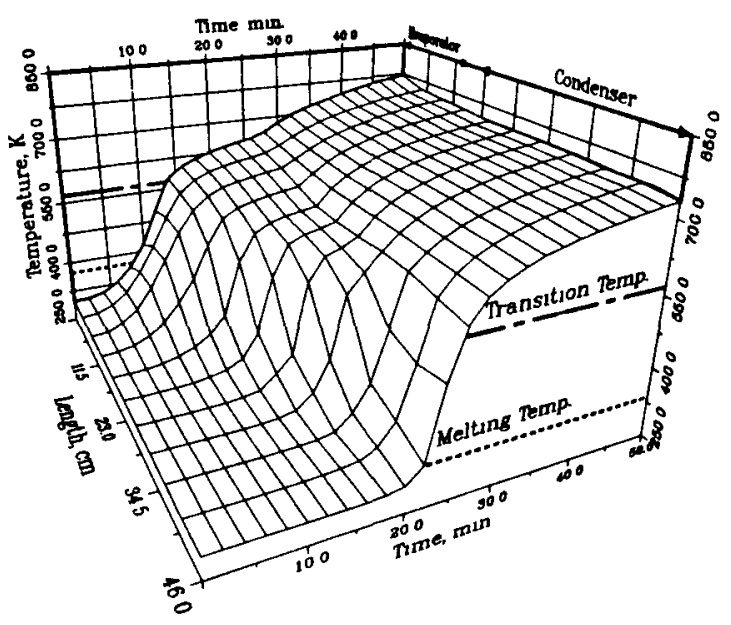

(b)

Fig. 6a,b Axial heat pipe temperature distributions during the start-up period with heat transport of $285.1 \mathrm{w}$.

the temperature drop across the pipe wall and the wick structure was calculated for the given heat input and heat pipe dimension when the vapor temperature was assumed to be the transition temperature. This temperature drop was about $14 \mathrm{~K}$. When the vapor temperature reached the transition temperature, the corresponding surface temperature at the evaporator would be $581 \mathrm{~K}$.

As shown in Figures $6 a$ and $6 b$ the surface temperatures at the evaporator increased rapidly up to the transition temperature, while temperatures at the condenser remained at about the initial temperature. Large axial temperature gradients were developed between the evaporator and condenser sections even though temperatures at the evaporator were greater than the melting temperature of potassium. This type of temperature profile has been observed when the evaporator underwent dry-out. Thus, the temperature distributions indicate that there is no significant evaporation of the working fluid at the evaporator and no significant vapor flow in the vapor space. The vapor pressure corresponding to the transition temperature is about $35 \times 10^{-4}$ $\mathrm{N} / \mathrm{cm}^{2}$. Therefore, the heat pipe was completely inactive.

When temperatures at the evaporator rose above the transition temperature, the rate of temperature increase at the evaporator slowed and the evaporator became near isothermal. Also, the temperature increase at the adjacent condenser section was accelerated. While temperatures at the condenser increased to the transition temperature, those at the evaporator remained almost constant until the end of condenser exceeded the transition temperature. These temperature distributions imply that the vaporization of the working fluid at the evaporator and the vapor flow in the vapor space were significant during this period. Thus, the measured temperature distributions showed that the heat pipe behaved as predicted around the transition temperature. Once the heat pipe reached near isothermal conditions, the heat pipe temperatures increased further until steady state conditions were established.

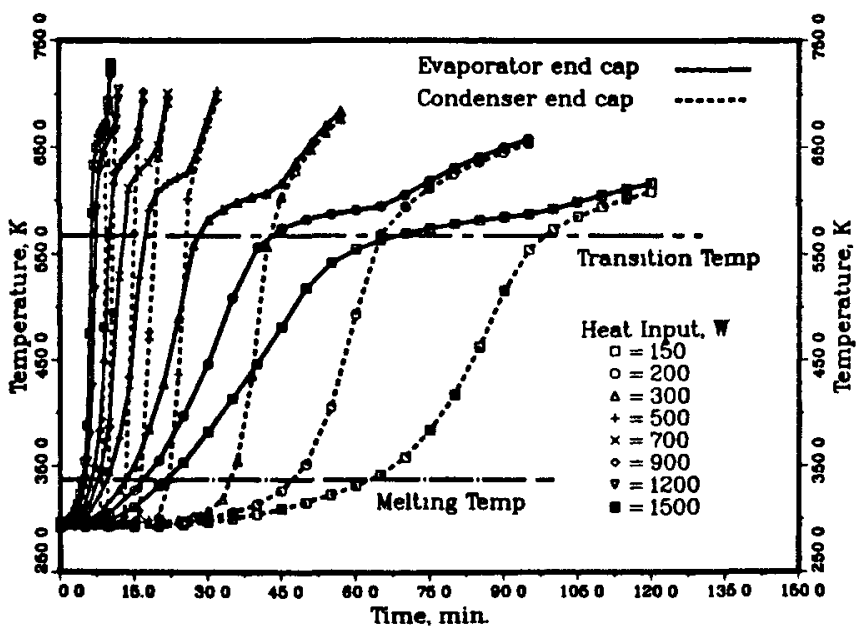

Fig. 7 Temperature history at the evaporator and condenser end caps for various heat inputs during the startup period.

Figure 7 shows the temperature history at the evaporator and condenser end caps with 
various heat inputs. For small heat inputs, the similar start-up behavior was predicted as shown in Figure $6 \mathrm{a}$ and the start-up process was much slower than for large heat inputs. For large heat inputs, the slower rate of temperature increase at the evaporator occurred at a higher temperature than the transition temperature since the heat input could be much larger than the heat removed by vaporization of the working fluid. Also, the temperature drop across the pipe wall and wick structure could be large. The start-up period was significantly reduced with a large heat input. For example, a tenfold increase in heat input resulted in about a tenfold faster start-up as long as the capillary limit was not exceeded.

To summarize the experimental results, the start-up process characteristics of the liquid metal heat pipe are described as shown in Figure 8. Also, the status of the working fluid in the wick structure and the flow regime in the vapor space were predicted. When the heat pipe temperature at the evaporator end cap is lower than the transition temperature $\left(T^{*}\right)$, the vapor pressure and the vapor density of the working fluid are extremely low; for example, $35 \times 10^{-4} \mathrm{~N} / \mathrm{cm}^{2}$ and $2.66 \times 10^{\circ}$ $7 \mathrm{~g} / \mathrm{cm}^{3}$, respectively, at the transition temperature $(567 \mathrm{~K})$ for potassium. Thus, for time $t<t_{2}$, the mode of heat transfer is mainly conduction along the pipe wall and wick structure. To simplify the mathematical model, an adiabatic boundary condition could be imposed at the interface between the wick and vapor space by neglecting the vapor flow. Also, For $t_{2} \leq t<t_{4}$ the continuum flow regime is established in part of the vapor space but the adiabatic boundary condition could still be applied at the interface, excluding the continuum flow regime. For $t>t_{4}$, the entire heat pipe is active.

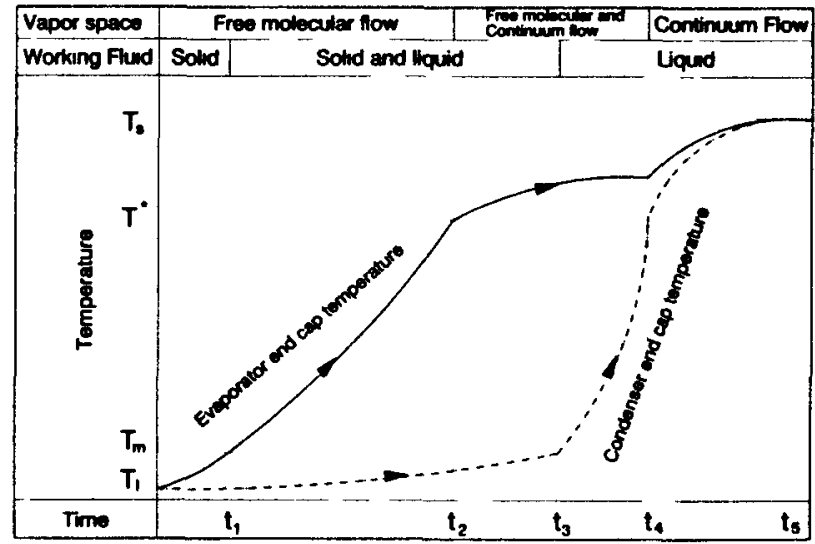

Fig. 8 A schematic diagram of the start-up process for liquid metal heat pipes.

Figure 9 shows the surface temperature distributions on the heat pipe when the evaporator experienced dry-out during the start-up period. The constant heat input of 1700 watts to the heater and the heat transport of 1250 watts (a radial heat flux of $17.75 \mathrm{w} / \mathrm{cm}^{2}$ ) through the heat pipe were measured at the steady state temperature $(1122 \mathrm{~K})$. The temperature distributions at the evaporator indicated that dry-out occurred before the working fluid at the condenser melted completely. However, later, the wick structure was rewetted by itself and the heat pipe performed well until it reached the steady state. Apparently the amount of liquid potassium returning from the condenser section was insufficient during the start-up process. Therefore, the heat input should be maintained at a value that is less than the heat transport capability at the steady state until the entire working fluid is completely melted.

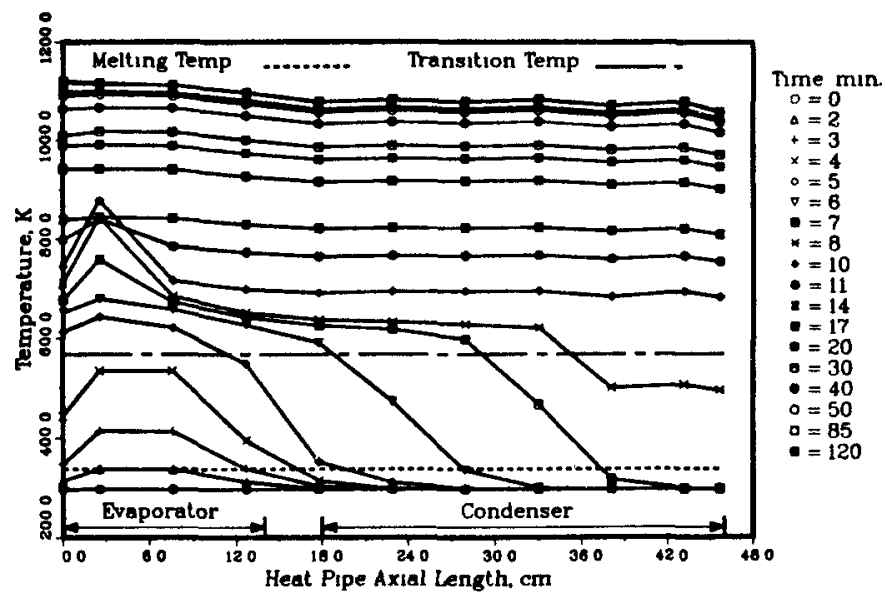

Fig. 9 Temperature distributions for the case of experiencing dry-out at the evaporator during the start-up period.

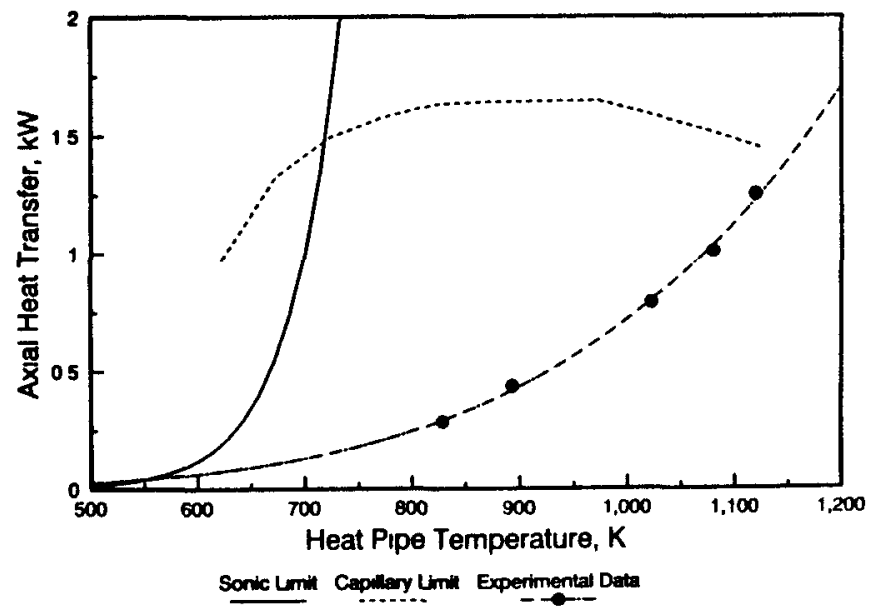

Fig. 10 Heat transport limits and actual axial heat transport for the potassium heat pipe at various operating temperatures.

Figure 10 shows the sonic limit, capillary limit, and experimental results for five different heat transports $(286,435,788$, 1008,1250 W). A constant heat input was applied at the evaporator during the entire test period. The sonic limit was calculated using the expression given by Chi (1976), while the capillary limit was estimated using 
Equation (4), assuming the working fluid is entirely in the liquid state. For the useful operating temperature range of $700 \mathrm{~K}$ to 1200 $K$, the average capillary limit calculated was about 1551 watts for the potassium heat pipe tested. For an operating temperature of 1122 $K$, dry-out was observed during the start-up period as shown in Figure 9 even though the actual axial heat transfer of 1250 watts was less than the capillary limit. A comparison shows that the axial heat transfer in the case of dry-out was 80.6 percent of the average capillary limit ( 1551 watts). When the heat (1008 watts) equivalent to 65 percent of the average capillary limit was transferred, dryout was not experienced during the entire operation and the heat pipe temperature reached about $1080 \mathrm{~K}$ at the steady state.

\section{CONCLUSIONS AND REMARKS}

A potassium heat pipe was tested with various heat inputs in a vacuum. The transition temperatures were calculated for potassium and sodium working fluids at various vapor space diameters. A comparison of the experimental results with the transition temperature for potassium showed that the heat pipe did not work until temperatures at the evaporator reached the transition temperature. Thus, vapor flow could be neglected to simplify the mathematical model when heat pipe temperatures are lower than the transition temperature. During the start-up period, larger heat inputs yielded faster start-ups, but heat input should be maintained at a level much less than the capillary limit at the steady state. Further analysis for liquid flow, including phase change during the start-up period, is needed to predict the maximum allowable heat input.

\section{ACKNOWLEDGMENTS}

Funding for this work was provided by the NASA Lewis Research Center under the direction of Jim Calogeras. Karl Baker and Mile Dustin also provided many valuable suggestions to build the experimental setup.

\section{REFERENCES}

Baker, K. W., Dustin, M. O., and Crane, R., - A Heat Receiver Design for Solar Dynamic Space Power Systems," NASA TM-102473, 1990.

Chi, s. W., 1976, Heat Pipe Theory and Practice, Hemisphere Publishing Co., Washington, U.S.A.

Deverall, J. E., Kemme, J. E., and Florschuetz, L. W., 1970, "Sonic Limitations and Startup Problems of Heat Pipes," LA-4518.

Eckert, E. R. G. and Drake, R. M., 1972, Analysis of Heat and Mass Transfer, McGrawHill Book Co., New York.

Faghri, A.; Buchko, M.; and Cao, Y., 1991, "A Study of High Temperature Heat Pipes with Multiple Heat Sources and Sinks: Part I Experimental Methodology and Frozen startup Profiles," J. of Heat Transfer, Vol. 113, Nov. 1991, pp.1003-1009.
Fujiwara, M., Sano, T., Suzuki, K., and Watanabe, S., "Thermal Analysis and Fundamental Tests on a Heat Pipe Receiver for a Solar Dynamics Space Power System," J. of Solar Energy Engineering, Vol. 112, August 1990, pp. 117-182.

Ivanovskil, M. N., sorokin, V. P., and Yagodkin, I. V., 1982, The Physical Principles of Heat Pipes, Clarendon Press, Oxford, United Kingdom.

Jang, J. H., 1988, "An Analysis of startup from the Frozen state and Transient Performance of Heat Pipes," Ph.D. Dissertation, Georgia Inst. of Tech., Atlanta, GA.

Jang, J. H., Faghri, A., Chang, W. S., and Mahefkey, E. T., "Mathematical Modeling and Analysis of Heat Pipe start-up from the Frozen State," J. of Heat Transfer, Vol. 112, August 1990, pp. 586-594.

Juhasz, A., 1991, "An Overview of the Lewis Research Center CSTI Thermal Management Program," AIAA-91-3528, 1991.

Tolubinsky, V. I., Shevchuk, E. N., and stambrovsky, v. D. , 1978, "study of LiquidMetal Heat Pipes Characteristics at startup and operation under Gravitation, "Proc. of $3 \mathrm{rd}$ Int. Heat Pipe Conf., pp. 274-282. 
Public reporting burden for this collection of information is estimated to average 1 hour per response, including the time for reviewing instructions, searching existing data sources, gathering and maintaining the data needed, and completung and reviewing the collection of information Send comments regarding this burden estumate or any other aspect of this collection of information, including suggestions for reducing this burden, to Washington Headquarters Services, Directorate for information Operations and Reports, 1215 Jefferson Davis Highway, Suite 1204, Arlington, VA 22202-4302, and to the Office of Management and Budget, Paperwork Reduction Project (0704-0188), Washington, DC 20503

\begin{tabular}{|l|l|l}
\hline 1. AGENCY USE ONLY (Leave blank) & $\begin{array}{c}\text { 2. REPORT DATE } \\
\text { April } 1992\end{array}$ & $\begin{array}{c}\text { 3. REPORT TYPE AND DATES COVERED } \\
\text { Final Contractor Report }\end{array}$
\end{tabular}

4. TITLE AND SUBTITLE

5. FUNDING NUMBERS

A Study of Start-Up Characteristics of a Potassium Heat Pipe from the Frozen State

\section{AUTHOR(S)}

Jong Hoon Jang

WU-590-13-21

C-NAS3-25266

Sverdrup Technology, Inc.

Lewis Research Center Group

2001 Aerospace Parkway

Brook Park, Ohio 44142

9. SPONSORING/MONITORING AGENCY NAMES(S) AND ADDRESS(ES)

National Aeronautics and Space Administration

Lewis Research Center

Cleveland, Ohio 44135-3191

8. Performing organization REPORT NUMBER

E-7031

10. SPONSORING/MONITORING AGENCY REPORT NUMBER

NASA CR-189173

\section{SUPPLEMENTARY NOTES}

Project Manager, James E. Calogeras, Power Technology Division, NASA Lewis Research Center, (216) 433-6146.

Prepared for the 1992 National Heat Transfer Conference sponsored by the American Society of Mechanical Engineers, San Diego, California, August 9-12, 1992.

\begin{tabular}{|l|l|l} 
12a. DISTRIBUTION/AVAILABILITY STATEMENT & 12b. DISTRIBUTION CODE
\end{tabular}

Unclassified - Unlimited

Subject Category 34

\section{ABSTRACT (Maximum 200 words)}

The start-up characteristics of a potassium heat pipe were studied both analytically and experimentally. Using the radiation heat transfer mode the heat pipe was tested in a vacuum chamber. The transition temperature calculated for potassium was then compared with the experimental results of the heat pipe with various heat inputs. These results show that the heat pipe was inactive until it reached the transition temperature. In addition, during the startup period, the evaporator experienced dry-out with a heat input smaller than the capillary limit calculated at the steady state. However, when the working fluid at the condenser was completely melted, the evaporator was rewetted without external aid. The start-up period was significantly reduced with a large heat input.

\begin{tabular}{|c|c|}
\hline $\begin{array}{c}\text { 14. SUBJECT TERMS } \\
\text { Heat pipe; Start-up; Potassium }\end{array}$ \\
$\begin{array}{c}\text { 17. SECURITY CLASSIFICATION } \\
\text { OF REPORT } \\
\text { Unclassified }\end{array}$ & $\begin{array}{c}\text { 18. SECURITY CLASSIFICATION } \\
\text { OF THIS PAGE } \\
\text { Unclassified }\end{array}$ \\
\hline
\end{tabular}

\begin{tabular}{|l|l|}
\hline \multirow{2}{*}{$\begin{array}{c}\text { 19. SECURITY CLASSIFICATION } \\
\text { OF ABSTRACT } \\
\text { Unclassified }\end{array}$} & $\begin{array}{c}\text { 15. NUMBER OF PAGES } \\
8\end{array}$ \\
\cline { 2 - 3 } & $\begin{array}{c}\text { 16. PRICE CODE } \\
\text { A02 }\end{array}$ \\
\hline \multicolumn{2}{|c|}{$\begin{array}{c}\text { Standard Form 298 (Rev 2-89) } \\
\text { Prescribed by ANSI Std Z39-18 } \\
298-102\end{array}$} \\
\hline
\end{tabular}


National Aeronautics and

Space Administration

Lewis Research Center

Cleveland, Ohio 44135

Otficial Business

Penalty for Private Use $\mathbf{\$ 3 0 0}$

ADDRESS CORRECTION REQUESTED

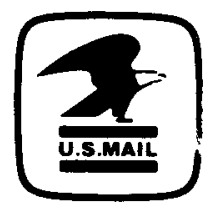

Postage and Fees Pdid Natıonal Aeronautics and Space Administration

NASA 45 